\title{
Assessing the patient safety culture and ward error reporting in public sector hospitals of Pakistan
}

\author{
Sara Rizvi Jafree ${ }^{1}$, Rubeena Zakar², Muhammad Zakria Zakar ${ }^{3}$ and Florian Fischer ${ }^{4^{*}}$ (D)
}

\begin{abstract}
Background: Very little research and practical efforts have been undertaken in public sector hospitals of Pakistan to promote error reporting and patient safety culture. Nurses in the country are key informants about the climate of error reporting and patient safety standards across wards in the hospital settings.

Methods: A questionnaire based on the Hospital Survey on Patient Safety Culture has been used to measure patient safety culture across 18 different wards in two public sector hospitals of Pakistan. Descriptive statistics have been used to analyze the perceptions of 309 nurse practitioners.

Results: Results show that more than $80 \%$ of nurses felt that their ward did not respond to reported errors and that excessive workload interfered in their ability to practice patient safety. Similarly, more than $70 \%$ of the nurses felt they were not supported for reporting errors and that their ward placed blame on them for reporting. An overwhelming majority of nurses felt that patient safety standards and error reporting were unfavorable across high-turnover wards like the Emergency, Gynecology and Maternity, General Medicine, Cardiology, Surgery, Nephrology, and Orthopedics wards.

Conclusion: Results imply that public hospitals, ward administrators, and health governing bodies in the country must take initiatives to introduce and monitor patient safety and error reporting systems in a more systematic and stringent manner.
\end{abstract}

Keywords: Patient safety, Error reporting, Pakistan, Nurses, Wards

\section{Background}

Error reporting is an important practice to ensure patient safety and to prevent adverse events in the hospital setting [1]. Multiple types of errors can commonly occur across hospital wards, leading to adverse events if not reported in a timely manner; this includes technical errors, medication and prescription errors, surgical planning errors, medical record errors, and surgical and post-operative errors [2-6]. Though human medical practitioner errors are inevitable, their frequency and culmination to adverse events for the patient can be mitigated through better research, monitoring and training, and organizational culture [7-9].

\footnotetext{
*Correspondence: f.fischer@uni-bielefeld.de

${ }^{4}$ School of Public Health, Department of Public Health Medicine, Bielefeld

University, P.O. Box 100 131, 33501 Bielefeld, Germany

Full list of author information is available at the end of the article
}

Nurses are integral front-line practitioners in the hospital setting. They have essential and significant knowledge of patient history, needs, and responses. Not only do nurses spend more time with patients, compared to doctors and physicians, but they have more responsibility and awareness about the care delivery received by the patient and the standards of safety practiced for each patient at the hospital setting $[10,11]$. Nurses have been evidenced to be the best practitioner to assess the climate of error reporting and the hospital culture regarding practices of patient safety [12-14].

Nearly all the lower and lower-middle class population of Pakistan depend on the public sector for health services [15]. However, low budget allocations and corruption in the health sector have sidelined patient safety standards and the monitoring of errors at the hospital settings [16]. Common barriers to patient safety found in public hospitals of the country include lack of standardization in 
procedures, systematic monitoring of prescriptions, favorable teamwork between practitioners, staffing and resources, and computerization of patient records [17-19]. Nearly all of the nurses in Pakistan are women practitioners [20]. Nurse practitioners in the country rotate across all the different wards of the hospitals during their first year of clinical practice and across their career, making them reliable sources for investigating patient safety culture.

There has been scant research with regard to the patient safety culture and error reporting in the health sector of Pakistan [21]. The objective of this study is to present descriptive statistics for patient safety standards: (i) across the four designation types of nurse respondents and (ii) across 18 wards of public sector hospitals in Pakistan.

\section{Methods}

This study is part of a $\mathrm{PhD}$ dissertation from which other sub-parts related to organizational culture, ethical violations, and workplace violence have already been published [22-24]. The study uses a quantitative study design based on cross-sectional data.

\section{Setting and sampling}

Two tertiary care public sector hospitals, from a total of 11 in Lahore, Pakistan, were randomly selected for sampling. Tertiary level public sector hospitals in Pakistan operate diverse and varied medical wards, catering to the following 18 specialties of Anesthesiology, Cardiology, Dermatology, Emergency, ENT (Ear, Nose, and Throat), Gastroenterology, General Medicine, Gynecology and Maternity, Nephrology, Neurology, Oncology, Ophthalmology, Orthopedics, Pathology, Pediatrics, Radiology, Surgery, and Urology. Each of these wards has been sampled in this study. Each nurse designation has been sampled, including nurse instructors, nurse ward heads, staff nurses, and student nurses. Student nurses form part of the clinical healthcare provider workforce in public sector hospitals after 3 months of training, due to shortages of staff. The General Medicine, Surgery, Gynecology and Maternity, and Emergency wards comprise of the biggest departments across the hospitals. Only nurses who had worked for more than 1 year in a public sector tertiary care hospital of Pakistan were included in the sample. Further details about sample have been reported in another paper [22].

\section{Instrument}

An internationally validated tool, the Survey to Solicit Information about the Culture of Reporting, developed by the Institute for Safe Medical Practices, was used [25]. This tool has been used by other researchers to assess the patient safety culture and error reporting practices in hospitals [26-29]. From a total of 13 questions, we chose to use seven, based on relevancy for our study and hospital environment of the country. Respondents were provided a summarized list of different errors that can occur in the hospital setting. Seven questions/statements from the survey were included in this study, which measure the culture of error reporting in a hospital and indicate how comfortable the respondents are in sharing errors at the workplace with their supervisors and coworkers. The scale has a 4-point rating scale, which indicates respondent extent of agreement with each item. The response categories include: $1=$ strongly agree, $2=$ agree, $3=$ disagree, and $4=$ strongly disagree . Categories were further dichotomized to present findings, with categories 1 and 2 compounded to represent 'yes' and categories 3 and 4 compounded to represent 'no'. Categories were further dichotomized to present findings, with categories 1 and 2 compounded to represent 'yes' and categories 3 and 4 compounded to represent 'no'. Two of the seven items (the last two questions in Table 2) had to be reverse-coded so that the scoring was aligned across all items of the tool.

\section{Data collection}

The survey was distributed during a period of three months (November 2013 to January 2014). Nurses from each ward of the two hospitals were invited to complete the survey by providing them with a cover letter informing about the research aims. This was done in the ward head office, where all nurses are required to visit daily for signing an attendance register. Surveys were completed, in the time of $20-35 \mathrm{~min}$ each, in reserved rooms of the nursing schools of both hospitals. The first author of this paper or one of the two research assistants were present to answer questions related to the survey. Completed surveys were sealed by the nurses and placed in a drop box in the nursing school or college. There are between 1034 and 1236 registered nurses in each of the hospital sampled. It was decided to distribute a total of 804 questionnaires, 402 to each hospital, more than double that of the target sample, to safely meet the target of 386 nurses. In total, of the 804 questionnaires, a final 309 were returned complete and included in the final analysis. The response rate was low at $38.4 \%$, but similar to those reported by international literature for studies on nurse perceptions about organizational culture. This sample, included in the final analysis, comprised of two nurse supervisors (one from each hospital), 205 staff nurses, 40 nurse ward heads, 11 nurse instructors, and 51 nurse students. Complete details of the data collection and sample can be found in a previous publication [22].

\section{Data analysis}

Raw data was first entered into Excel and then was transferred into SPSS 17.0 for analysis. Regression tests 
of association between organizational culture and patient safety have been reported in a previous paper [22]. For this paper, descriptive statistics have been used to show the socio-demographic characteristics of nurse respondents, the culture of patient safety in hospitals as perceived by each nurse designation, and the culture of patient safety across different wards in the country.

\section{Ethics}

Permission for research was taken from the Institutional Review Board, University of the Punjab, and also from the hospitals and nursing institutes where data collection took place. Anonymity of participants was assured by not taking any names of respondents. Respondents were informed and sought permission for survey completion through a cover letter which described the objectives of the research. Surveys were completed in private rooms of nursing schools to ensure complete confidentiality. Validity and reliability was assured through the use of an internationally standardized tool, and the presence of the researcher while survey was being filled to answer any queries by the respondents.

\section{Results}

The socio-demographic characteristics of the sample are presented in Table 1 . The average age of nurse respondents was 30.5 years $(\mathrm{SD}=9.9)$. Nearly all of the nurses were from Punjab (97.4\%) and a majority (56.3\%) had diploma degrees. Almost two-thirds (65.7\%) of the nurse respondents were staff nurses, and the sampling of designations reflected the actual weightage of nurse designation distribution across public sector hospitals of the country.

With regard to the seven questions pertaining to patient safety culture, the results for all nurses, as listed in Table 2, were (i) $71.8 \%$ felt that practitioners were not supported for reporting medical errors, (ii) $70.6 \%$ felt that their workload interfered in their ability to practice patient safety, (iii) $68.0 \%$ felt that they had not been communicated by hospital seniors that patient safety was a high priority, (iv) $67.0 \%$ felt that they could not openly communicate opinions about patient care practices, (v) $64.2 \%$ of nurse respondents felt that their ward did not respond to reported errors in order to improve patient safety, (vi) $63.1 \%$ were not comfortable in reporting errors made by their coworkers, and (vii) $42.3 \%$ felt that their ward placed blame on individuals for reporting errors.

The perceptions about patient safety culture of nurses from the four different designations have been presented in Table 3. Majority of the four nurse designations (student nurse, staff nurse, nurse ward head, and nurse instructor/supervisor) believed that (i) individuals are not supported for reporting medical errors, (ii) they
Table 1 Socio-demographic and employment characteristics of nurse respondents $(n=309)$

\begin{tabular}{|c|c|}
\hline Nurse characteristics & Total $n(\%)$ \\
\hline \multicolumn{2}{|l|}{ Age (in years) } \\
\hline $20-29$ & $161(52.1 \%)$ \\
\hline $30-39$ & 87 (28.2\%) \\
\hline 40 & $61(19.7 \%)$ \\
\hline \multicolumn{2}{|l|}{ Marital status } \\
\hline Never married & $130(42.1 \%)$ \\
\hline Ever married & 179 (57.9\%) \\
\hline \multicolumn{2}{|l|}{ Nurse income (PKR) } \\
\hline $5000-19,999$ & $56(18.1 \%)$ \\
\hline $20,000-39,999$ & $154(49.8 \%)$ \\
\hline$\geq 40,000$ & 99 (32.1\%) \\
\hline \multicolumn{2}{|l|}{ Province } \\
\hline Punjab & $301(97.4 \%)$ \\
\hline Sindh/Baluchistan/KPK & $8(2.6 \%)$ \\
\hline \multicolumn{2}{|l|}{ Religion } \\
\hline Islam & $231(74.7 \%)$ \\
\hline Minority (Christian/Hindu) & $78(25.3 \%)$ \\
\hline \multicolumn{2}{|l|}{ Ward } \\
\hline Emergency & $55(17.8 \%)$ \\
\hline Gynecology and Maternity & $45(14.6 \%)$ \\
\hline General Medicine & $43(13.9 \%)$ \\
\hline Cardiology & $39(12.6 \%)$ \\
\hline Internal Medicine & $32(10.4 \%)$ \\
\hline Surgery & $28(9.1 \%)$ \\
\hline Orthopedics & $18(5.8 \%)$ \\
\hline ENT & $16(5.2 \%)$ \\
\hline Others & $31(10.7 \%)$ \\
\hline \multicolumn{2}{|l|}{ Nursing degree } \\
\hline Diploma & $174(56.3 \%)$ \\
\hline B.Sc. Nursing & $120(38.8 \%)$ \\
\hline M.Sc. Nursing & $15(4.9 \%)$ \\
\hline \multicolumn{2}{|l|}{ Nurse designation } \\
\hline Student & $51(16.5 \%)$ \\
\hline Staff nurse & $205(66.3 \%)$ \\
\hline Head nurse & 40 (12.9\%) \\
\hline Nurse instructor/supervisor & $13(4.2 \%)$ \\
\hline \multicolumn{2}{|l|}{ Government contract } \\
\hline Contractual & $133(43.0 \%)$ \\
\hline Permanent & $176(57.0 \%)$ \\
\hline \multicolumn{2}{|c|}{ Work extra hours in evening or night } \\
\hline Yes & $124(40.1 \%)$ \\
\hline No & $185(59.9 \%)$ \\
\hline
\end{tabular}


Table 2 Culture of patient safety in public hospitals as perceived by nurse respondents $(n=309)$

\begin{tabular}{llll}
\hline Construct & Question/statement & Yes & No \\
& & $n(\%)$ & $n(\%)$ \\
\hline Priority & I have been communicated by hospital seniors that patient safety is a high priority & $99(32.0 \%)$ & $210(68.0 \%)$ \\
Support & Individuals are supported for reporting medical errors & $87(28.2 \%)$ & $222(71.8 \%)$ \\
Comfort & I feel comfortable reporting errors made by co-workers & $114(36.9 \%)$ & $195(63.1 \%)$ \\
Ward response & My ward acts on reported information related to errors to improve patient safety & $110(35.6 \%)$ & $199(64.4 \%)$ \\
Communication & I can openly communicate my opinions about patient care practices & $102(33.0 \%)$ & $207(67.0 \%)$ \\
Ward blame & My ward places blame on individuals when an error is reported & $131(42.4 \%)$ & $178(57.6 \%)$ \\
Workload & My workload interferes with my ability to practice patient safety & $219(70.9 \%)$ & $90(29.1 \%)$ \\
\hline
\end{tabular}

could not openly communicate their opinions about patient care practices, and (iii) their ward placed blame on individuals who reported errors. With regard to the construct of priority, majority of the three designations of staff nurses, nurse ward heads, and nurse instructor/supervisors, agreed that hospital seniors did not communicate that patient safety is a high priority. However, the majority of student nurses indicated that hospital seniors did communicate that patient safety is a high priority.

Whereas the majority of three designations, student nurses, staff nurse, and nurse ward heads felt they could not openly communicate their opinions about patient care practices and nurse instructor/supervisor felt the opposite. Similarly, whereas the majority of the same three designations (student nurses, staff nurse, and nurse ward heads) felt that their ward did not act on reported information related to errors to improve patient safety, nurse instructor/supervisor believed the contrary. Though the majority of nurse instructor/supervisors believed that the excessive workload interfered with their ability to practice patient safety, the majority of student nurses, staff nurse, and nurse ward heads believed the converse.

The seven constructs used to measure patient safety culture are described in Table 4, in terms of patient safety remaining unfavorable due to (a) no prioritization (for patient safety), (b) no support (for reporting errors), (c) no comfort (in reporting errors of coworkers), (d) no ward response (to improve patient safety, on reported errors), (e) no communication (about patient care practices), (f) ward blames (individuals who report errors), and (g) workload interferes (in ability to practice patient safety). The majority of nurse respondents ( $n=245 ; 79 \%$ of the sample) were sampled from the wards of Emergency, Gynecology and Maternity, General Medicine, Cardiology, Surgery, Nephrology, and Orthopedics, which is consistent with public sector ward sizes in the public sector. Regardless of the type of ward, all seven patient safety measures (communication, support, comfort, ward response, practitioner opinion about care practices, ward blames, and workload) show unfavorable statistics, ranging from $31 \%$ to $100 \%$. This implies that

Table 3 Culture of patient safety as perceived by different nurse designations ( $n=309$ )

\begin{tabular}{|c|c|c|c|c|c|c|}
\hline \multirow[t]{2}{*}{ Construct } & \multirow[t]{2}{*}{ Question/statement } & $\begin{array}{l}\text { All } \\
n=309\end{array}$ & $\begin{array}{l}\text { Student } \\
n=51\end{array}$ & $\begin{array}{l}\text { Staff } \\
n=205\end{array}$ & $\begin{array}{l}\text { Head } \\
n=40\end{array}$ & $\begin{array}{l}\text { Instructor/supervisor } \\
n=13\end{array}$ \\
\hline & & $\begin{array}{l}\text { No } \\
n(\%)\end{array}$ & $\begin{array}{l}\text { No } \\
n(\%)\end{array}$ & $\begin{array}{l}\text { No } \\
n(\%)\end{array}$ & $\begin{array}{l}\text { No } \\
n(\%)\end{array}$ & $\begin{array}{l}\text { No } \\
n(\%)\end{array}$ \\
\hline Priority & $\begin{array}{l}\text { I have been communicated by hospital } \\
\text { seniors that patient safety is a high priority }\end{array}$ & $210(68.0 \%)$ & $13(25.5 \%)$ & $142(69.3 \%)$ & $28(70.0 \%)$ & $9(69.2 \%)$ \\
\hline Support & $\begin{array}{l}\text { Individuals are supported for reporting } \\
\text { medical errors }\end{array}$ & $222(71.8 \%)$ & 39 (76.5\%) & $142(69.3 \%)$ & $29(72.5 \%)$ & 12 (92.3\%) \\
\hline Comfort & $\begin{array}{l}\text { I feel comfortable reporting errors made } \\
\text { by co-workers }\end{array}$ & 195 (63.1\%) & $36(70.6 \%)$ & $130(63.4 \%)$ & $25(62.5 \%)$ & $4(30.8 \%)$ \\
\hline Ward response & $\begin{array}{l}\text { My ward acts on reported information } \\
\text { related to errors to improve patient safety }\end{array}$ & 199 (64.2\%) & $35(68.6 \%)$ & $133(64.9 \%)$ & $25(62.5 \%)$ & $6(46.2 \%)$ \\
\hline Communication & $\begin{array}{l}\text { I can openly communicate my opinions } \\
\text { about patient care practices }\end{array}$ & 207 (67.0\%) & 38 (74.5\%) & $134(65.4 \%)$ & $25(62.5 \%)$ & 10 (76.9\%) \\
\hline Ward blame & $\begin{array}{l}\text { My ward places blame on individuals when } \\
\text { an error is reported }\end{array}$ & $178(57.4 \%)$ & $30(58.8 \%)$ & $119(58.0 \%)$ & $20(50.0 \%)$ & $9(69.2 \%)$ \\
\hline Workload & $\begin{array}{l}\text { My workload interferes with my ability to } \\
\text { practice patient safety }\end{array}$ & $90(29.0 \%)$ & 17 (33.3\%) & $56(27.3 \%)$ & $10(25.0 \%)$ & 7 (53.8\%) \\
\hline
\end{tabular}




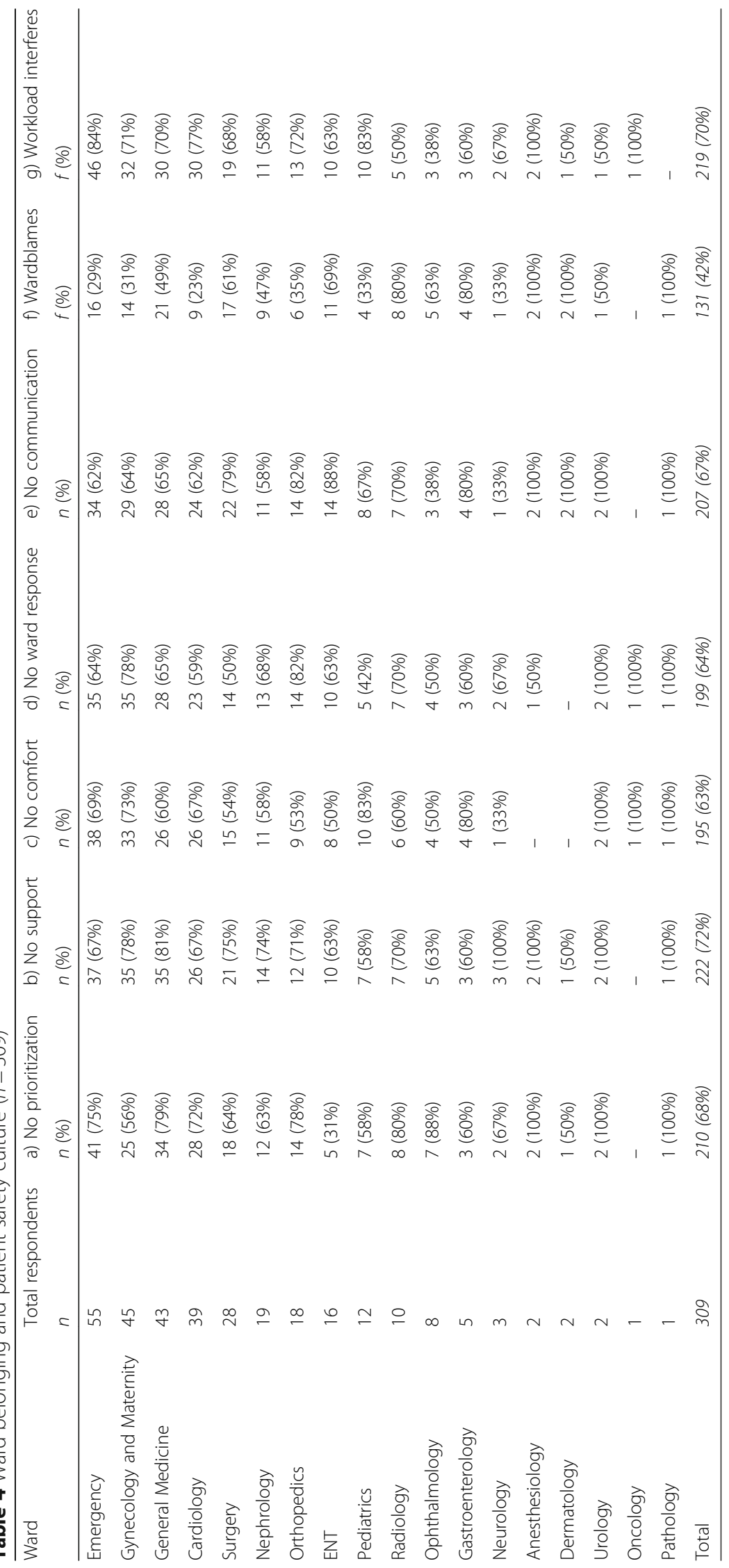


unfavorable patient safety standards and error reporting is a reality across the entire public sector hospitals of the country, regardless of ward type.

Across the seven wards of emergency, gynecology and maternity, general medicine, cardiology, surgery, nephrology, and orthopedics, the majority of nurse respondents felt that (a) they were not communicated by seniors that patient safety was a priority (b) they were not supported in reporting errors, (c) they were not comfortable in reporting the errors made by coworkers, (d) ward does not act on information related to errors to improve patient safety, (e) they could not openly communicate their opinions about patient care practices, (f) wards blame individuals when an error is reported, and (g) their workload interferes with their ability to practice patient safety.

\section{Discussion}

This is one of the first studies of its kind in Pakistan which highlights the problems faced by health practitioners in securing patient safety and preventing adverse events during care delivery. Though currently one-third of Pakistanis utilize public health services [15], scholars estimate that nearly $66 \%$ of the population, especially the poor and rural populations, are in need of access and services from this sector [30]. The major barriers preventing the public from utilizing public health services is both the unfavorable patient safety culture and the reluctance of practitioners in reporting errors [31, 32]. A recent conference in Islamabad, the capital of Pakistan, suggests that there is a desperate need for the prioritization of patient safety across all hospitals of the nation [33]. The results of the study suggest that nurses perceive the culture in public hospitals of Pakistan to be punitive and that individuals are not supported or made to feel comfortable in reporting errors. In fact, results suggest that practitioners are blamed by their ward for reporting errors. Additionally, senior practitioners and administrators do not emphasize that error reporting and patient safety practices are a priority during healthcare delivery. Previous studies confirm that public hospitals in Pakistan maintain punitive cultures in order to support corruption, traditional work norms, and administrative hierarchies [34]. Individuals who attempt to challenge customs by reporting errors, of their own or their coworkers, are censured and excluded from the ward teams to dissuade the emergence of a culture of reporting [32].

The fact that our findings indicate that the majority of nurse instructors/supervisors were the only designation to feel that they could openly communicate their opinions about patient care practices, gives credence to the hierarchal culture in the health sector of Pakistan. Research suggests that nurse instructors/supervisors, due to their higher status and superior hierarchal position, feel less threatened and embarrassed about communicating their opinions in general compared to their juniors, subordinates, or students [35]. Nurse instructors/supervisors, unlike the other three nurse designations, also believed that the ward did act on reported information related to errors to improve patient safety. This may be because nurse instructors/supervisors are largely responsible for ward response levels and thus are reluctant to admit that preventing adverse events may be their fault [36]. It was also found that when errors are reported, the ward response to prevent adverse events and secure patient safety is not favorable. This may be due to the absence of error reporting systems and systematic plans within the wards to track and prevent errors and adverse events [37]. There is a grave need for the formal and hidden curriculum, on-the-job training, and official ward objectives to include plans for the sharing and mitigation of errors, which is currently not a reality in the health sector of the country $[38,39]$. The results extend our previous research, which found that when a favorable organizational culture exists, the hospital and ward response to error reporting and patient safety will be more favorable [22]. It was found that majority of the student nurses believed that hospital seniors did communicate that patient safety is a high priority. This may be because student nurses are still theoretically studying about patient safety standards at their respective nursing school/ college; however, the indication is that on the job clinical training for practitioners needs to be improved [40].

Findings also revealed that the opinion of nurses regarding care practices and patient safety did not hold much importance. International literature suggests that when nurse care practices are given importance, patient safety is optimal, this is because nurses spend more time monitoring and caring for patients [12, 14]. Hospitals in Pakistan still function and rely on medical care plans as opposed to nursing care plans for the maintenance of patient safety standards. It was also found that practitioners were unable to report errors and secure patient safety because of excessive workload. Our findings are consistent with scholarship which points to critical shortages in staffing and resources, due to corruption of funds, misplacement of resources, and low budget allocation for the public health sector [12, 41]. Estimates show that the nurse to doctor, doctor to patient, and nurse to patient ratios in Pakistan are gravely below international standards [42]. Our results support the key role of autonomous nurse practitioners in creating an organizational culture which supports error sharing and patient safety.

With regard to the wards, findings show that the most frequented and busy wards in public sector hospitals of Pakistan (including Emergency, Gynecology and Maternity, 
General Medicine, Cardiology, Surgery, Nephrology, and Orthopedics) are highly associated with the absence of patient safety culture and error reporting. Studies from developed nations re-affirm that a high incidence of errors can occur in the following wards due to (i) Emergency and Critical Care Units-due to high stress, fatigue, and long working hours for practitioners [43, 44], (ii) Gynecology and Maternity wards-due to stress of delivering child safely, unexpected delivery complications, and dealing with anxious mothers and family attendants [45, 46], (iii) General Medicine wards-due to lack of time, specialist knowledge and over-confidence [47, 48], (iv) Cardiology wards-due to technical errors and misdiagnosis of medicine $[49,50]$, (v) Surgery wards-due to technical malfunctions, anesthesia administration and wound infections [51], (vi) Nephrology wards-due to errors of prediction and errors in sampling $[52,53]$ and (vii) Orthopedics wards-due to wrong-site surgery and medication errors $[54,55]$.

Collectively, the abovementioned wards are known to have higher error rates due to the nature of their work environment and service delivery, such as higher patient turnover, greater stress, increased mortality, and staffing and resource burden. Ultimately, non-reportage of errors in these high-patient-turnover wards means a greater risk for adverse events and patient mortality. There is need for longitudinal and sustained recording of errors in these wards and across public sector hospitals, in order to better understand the types of errors that occur and also to help plan relevant policies to mitigate errors across different wards [56]. Surprisingly, we found that the majority of student nurses, staff nurses, and nurse ward heads believed that the excessive workload did not interfere with their ability to practice patient safety. It may be that they wanted to emphasize the importance of reporting errors and introducing a culture and formal systems for patient safety practices, as opposed to highlighting the staffing and resource burden in public sector hospitals. Evidence suggests that levels of patient safety standards and error tracking systems can be maintained even when staffing is variable [57].

Although this study has limitations such as a small sample size, the cross-sectional design, and responses from only two hospitals, it presents important findings for the patient safety culture in public hospitals of Pakistan.

\section{Conclusions}

Our findings suggest that there is a key role to be played by nurse and ward leadership in the introduction, direction, and management of error tracking systems, the culture of error reporting, and the overall patient safety culture in Pakistan. Though legislation by governing bodies like the Health Ministry and the Pakistan Medical and Dental Council are important, the individual ward administrators across public hospitals can become front runners in developing strategies for care delivery, error reporting, and the prevention of adverse events. It is hoped that the efforts and success of individual wards can become benchmarks to be emulated across other wards in the public sector hospitals of the country.

\begin{abstract}
Acknowledgements
We acknowledge support of the publication fee by Deutsche Forschungsgemeinschaft and the Open Access Publication Funds of Bielefeld University.

Funding

None.

Availability of data and materials

Data is available upon request.

Authors' contributions

SRJ and RZ designed the study. SRJ analyzed and interpreted the data. RZ supported this process. SRJ drafted the manuscript. MZZ and FF revised the manuscript critically for important intellectual content. All authors read and approved the final manuscript.
\end{abstract}

Ethics approval and consent to participate

Ethical approval was obtained by the Institutional Review Board, University of the Punjab, and also from the hospitals and nursing institutes where data collection took place.

\section{Consent for publication}

Written informed consent for data collection and publication was provided by study participants.

\section{Competing interests}

The authors declare that they have no competing interests.

\section{Publisher's Note}

Springer Nature remains neutral with regard to jurisdictional claims in published maps and institutional affiliations.

\section{Author details}

${ }^{1}$ Forman Christian College, Sociology Department, A Chartered University, FCC, Gulberg, P.O. Box 54000, Lahore, Pakistan. ${ }^{2}$ Institute of Social and Cultural Studies, University of the Punjab, Lahore, Pakistan. ${ }^{3}$ Faculty of Behavioral and Social Sciences, Institute of Social and Cultural Studies, University of the Punjab, Lahore, Pakistan. ${ }^{4}$ School of Public Health, Department of Public Health Medicine, Bielefeld University, P.O. Box 100 131, 33501 Bielefeld, Germany.

Received: 6 July 2017 Accepted: 22 August 2017

Published online: 04 September 2017

\section{References}

1. Hughes R: Error reporting and disclosure-patient safety and quality: an evidence-based handbook for nurses. 2008.

2. Lewis PJ, Dornan T, Taylor D, Tully MP, Wass V, Ashcroft DM. Prevalence, incidence and nature of prescribing errors in hospital inpatients. Drug Saf. 2009;32(5):379-89.

3. Tam VC, Knowles SR, Cornish PL, Fine N, Marchesano R, Etchells EE. Frequency, type and clinical importance of medication history errors at admission to hospital: a systematic review. Can Med Assoc J. 2005;173(5):510-5.

4. Benner P, Malloch K, Sheets V, Bitz K, Emrich L, Thomas MB, Bowen K, Scott K, Patterson L, Schwed K. TERCAP: Creating a national database on nursing errors. Harv Health Policy Rev. 2006:7(1):48-63.

5. Johnstone $\mathrm{M}-\mathrm{J}$, Kanitsaki $\mathrm{O}$. The ethics and practical importance of defining, distinguishing and disclosing nursing errors: a discussion paper. Int J Nurs Stud. 2006:43(3):367-76.

6. Rothschild JM, Landrigan CP, Cronin JW, Kaushal R, Lockley SW, Burdick E, Stone PH, Lilly CM, Katz JT, Czeisler CA. The critical care safety study: the 
incidence and nature of adverse events and serious medical errors in intensive care. Crit Care Med. 2005;33(8):1694-700.

7. Benn J, Koutantji M, Wallace L, Spurgeon P, Rejman M, Healey A, Vincent C. Feedback from incident reporting: information and action to improve patient safety. Qual Saf Health Care. 2009;18(1):11-21.

8. Kaldjian LC, Jones EW, Wu BJ, Forman-Hoffman VL, Levi BH, Rosenthal GE. Reporting medical errors to improve patient safety: a survey of physicians in teaching hospitals. Arch Intern Med. 2008;168(1):40-6.

9. Howanitz PJ. Errors in laboratory medicine: practical lessons to improve patient safety. Arch Pathol Lab Med. 2005;129(10):1252-61.

10. Mayo AM, Duncan D. Nurse perceptions of medication errors: what we need to know for patient safety. J Nurs Care Qual. 2004;19(3):209-17.

11. Nadzam DM. Nurses' role in communication and patient safety. J Nurs Care Qual. 2009;24(3):184-8.

12. Laschinger HKS, Leiter MP. The impact of nursing work environments on patient safety outcomes: the mediating role of burnout engagement. J Nurs Adm. 2006;36(5):259-67.

13. Kim J, An K, Kim MK, Yoon SH. Nurses' perception of error reporting and patient safety culture in Korea. West J Nurs Res. 2007;29(7):827-44.

14. Armstrong KJ, Laschinger $\mathrm{H}$. Structural empowerment, magnet hospital characteristics, and patient safety culture: making the link. J Nurs Care Qual. 2006;21(2):124-32.

15. Akram M, Khan FJ. Health care services and government spending in Pakistan. East Asian Bureau of Economic Research; 2007.

16. Ahmed J, Shaikh BT. An all time low budget for healthcare in Pakistan. J Coll Phys Surg Pak. 2008;18(6):388.

17. Siddiqi S, Elasady R, Khorshid I, Fortune T, Leotsakos A, Letaief M, Qsoos S, Aman R, Mandhari A, Sahel A. Patient safety friendly hospital initiative: from evidence to action in seven developing country hospitals. Int J Qual Health Care. 2012;24(2):144-51.

18. Zafar SN, McQueen KK. Surgery, public health, and Pakistan. World J Surg. 2011;35(12):2625-34.

19. Rohra DK, Das N, Azam Sl, Solangi NA, Memon Z, Shaikh AM, Khan NH. Drug-prescribing patterns during pregnancy in the tertiary care hospitals of Pakistan: a cross sectional study. BMC Pregnancy Childbirth. 2008;8(1):24

20. Ahmed F, Mahmud S, Hatcher J, Khan SM. Breast cancer risk factor knowledge among nurses in teaching hospitals of Karachi, Pakistan: a crosssectional study. BMC Nurs. 2006:5(1):6.

21. Nishtar S. Choked pipes: reforming Pakistan's mixed health system. In: JSTOR; 2009.

22. Jafree SR, Zakar R, Zakar MZ, Fischer F. Nurse perceptions of organizational culture and its association with the culture of error reporting: a case of public sector hospitals in Pakistan. BMC Health Serv Res. 2016;16(1):3.

23. Jafree SR, Zakar R, Fischer F, Zakar MZ. Ethical violations in the clinical setting: the hidden curriculum learning experience of Pakistani nurses. BMC Med Ethics. 2015;16(1):16

24. Jafree SR. Workplace violence against women nurses working in two public sector hospitals of Lahore. Nursing Outlook: Pakistan; 2017.

25. Pathways for Medication Safety: Leading a Strategic Planning Effort [http:// www.ismp.org/tools/pathwaysection1.pdf]

26. Sorra J, Famolaro T, Dyer N, Nelson D, Khanna K. Hospital survey on patient safety culture: 2010 user comparative database report (AHRQ publication no 10-0026) Rockville. Agency for Healthcare Research and Quality: MD; 2010.

27. Bussone K, Belknap S: Leading a strategic planning effort from the American Hospital Association. Health Research and Educational Trust, and the Institute for Safe Medication Practices Chicago. 2002.

28. Gorini A, Miglioretti M, Pravettoni G. A new perspective on blame culture: an experimental study. J Eval Clin Pract. 2012;18(3):671-5.

29. Farley DO, Haviland A, Champagne S, Jain A, Battles JB, Munier WB, Loeb J. Adverse-event-reporting practices by US hospitals: results of a national survey. Qual Saf Health Care. 2008;17(6):416-23.

30. Shaikh BT, Hatcher J. Health seeking behaviour and health service utilization in Pakistan: challenging the policy makers. J Public Health. 2005:27(1):49-54.

31. Khowaja K, Nizar R, Merchant RJ, Dias J, Bustamante-Gavino I, Malik A. A systematic approach of tracking and reporting medication errors at a tertiary care university hospital, Karachi, Pakistan. Ther Clin Risk Manag. 2008:4(4):673-9.

32. Malik MR, Alam AY, Mir AS, Malik GM, Abbas SM: Attitudes and perceived barriers of tertiary level health professionals towards incident reporting in Pakistan. N Am J Med Sci. 2010;2(2).
33. Islamabad Declaration on Patient Safety, 1st International Conference on Patient Safety (ICPS), 8th May 2016, Islamabad. http://www.drzaki.org/wpcontent/uploads/2014/11/Declaration-Patient-Safety.pdf.

34. Shaikh K, Lalani SB. Disclosure of medical error. J Ayub Med College. 2011; 23(3):157-8.

35. Nacioglu A. As a critical behavior to improve quality and patient safety in health care: speaking up! Saf Health. 2016;2(1):10.

36. Armstrong SJ, Rispel LC, Penn-Kekana L. The activities of hospital nursing unit managers and quality of patient care in South African hospitals: a paradox? Glob Health Action. 2015;8(1):26243.

37. Beg M. Views of health care providers on medical errors in Karachi, Pakistan. Value Health. 2014;17(3):A184.

38. Morey JC, Simon R, Jay GD, Wears RL, Salisbury M, Dukes KA, Berns SD. Error reduction and performance improvement in the emergency department through formal teamwork training: evaluation results of the MedTeams project. Health Serv Res. 2002;37(6):1553-81.

39. Croskerry P, Wears RL, Binder LS. Setting the educational agenda and curriculum for error prevention in emergency medicine. Acad Emerg Med. 2000;7(11):1194-200

40. Andrews M, Roberts D. Supporting student nurses learning in and through clinical practice: the role of the clinical guide. Nurse Educ Today. 2003:23(7):474-81

41. Williams ES, Manwell LB, Konrad TR, Linzer M. The relationship of organizational culture, stress, satisfaction, and burnout with physicianreported error and suboptimal patient care: results from the MEMO study. Health Care Manag Rev. 2007:32(3):203-12.

42. Ghaffar A, Kazi BM, Salman M. Health care systems in transition III. Pakistan, Part I. An overview of the health care system in Pakistan. J Public Health. 2000;22(1):38-42.

43. Benkirane RR, Redouane R, Haimeur CC, El Kettani SSEC, Azzouzi AA, Mdaghri Alaoui A, Thimou AA, Nejmi MM, Maazouzi WW, Madani NN. Incidence of adverse drug events and medication errors in intensive care units: a prospective multicenter study. J Patient Saf. 2009:5(1):16-22.

44. Mohammadnejad E, Ehsani KKSR, Salari A, Sajjadi A, Hajiesmaeelpour A: Refusal in reporting medication errors from the perspective of nurses in Emergency Ward. 2013.

45. Thompson S, Neal S, Clark V. Clinical risk management in obstetrics: eclampsia drills. Qual Saf Health Care. 2004;13(2):127.

46. Nielsen $\mathrm{P}$, Mann S. Team function in obstetrics to reduce errors and improve outcomes. Obstet Gynecol Clin N Am. 2008;35(1):81-95.

47. Makeham MA, Stromer S, Bridges-Webb C, Mira M, Saltman D, Cooper C, Kidd MR. Patient safety events reported in general practice: a taxonomy. Qual Saf Health Care. 2008;17(1):53-7.

48. Berner ES, Graber ML. Overconfidence as a cause of diagnostic error in medicine. Am J Med. 2008;121(5):S2-S23.

49. LaPointe NMA, Jollis JG. Medication errors in hospitalized cardiovascular patients. Arch Intern Med. 2003;163(12):1461-6.

50. Roelandt J, van Dorp WG, Bom N, Laird JD, Hugenholtz PG. Resolution problems in echocardiology: a source of interpretation errors. Am J Cardiol. 1976:37(2):256-62

51. Rogers SO, Gawande AA, Kwaan M, Puopolo AL, Yoon C, Brennan TA, Studdert DM. Analysis of surgical errors in closed malpractice claims at 4 liability insurers. Surgery. 2006;140(1):25-33.

52. Cirillo M, Anastasio P, De Santo NG. Relationship of gender, age, and body mass index to errors in predicted kidney function. Nephrol Dial Transplant. 2005;20(9):1791-8

53. Vessal G. Detection of prescription errors by a unit-based clinical pharmacist in a nephrology ward. Pharm World Sci. 2010;32(1):59-65.

54. Weiner BK, Venarske J, Yu M, Mathis K. Towards the reduction of medication errors in orthopedics and spinal surgery: outcomes using a pharmacist-led approach. Spine. 2008:33(1):104-7.

55. Kilpatrick J. Medical errors and wrong-site surgery. Orthopedics. 2002;25(3):288.

56. Elden NMK, Ismail A. The importance of medication errors reporting in improving the quality of clinical care services. Glob J Health Sci. 2016;8(8):243.

57. Aiken LH, Sermeus W, Van den Heede K, Sloane DM, Busse R, McKee M, Bruyneel L, Rafferty AM, Griffiths P, Moreno-Casbas MT. Patient safety, satisfaction, and quality of hospital care: cross sectional surveys of nurses and patients in 12 countries in Europe and the United States. BMJ. 2012;344:e1717 